\title{
A propósito de la traducción filipina de Tirant lo Blanch. Joanot Martorell, Tirante el Blanco. Ang Maputing Kabalyero (traducción al filipino de Jeannifer Zabala Priel e Isaac Donoso Jiménez, Quezon City, CentralBooks, 2010)
}

\author{
ISAAC DONOSO JIMÉNEZ \\ (UNIVERSIDAd NoRMAL DE FiLIPINAS) \\ isaacdonoso@yahoo.es \\ Recibido: abril de 2011. Aceptado: junio de 2011
}

\begin{abstract}
Resumen: A pesar de la distancia geográfica, la literatura de la Corona de Aragón ha ejercido una importante influencia en la creación literaria del Archipiélago Filipino. La presencia hispánica continuada desde el siglo XVI introdujo formas literarias autóctonas de Europa. Así, el romancero hispánico y los libros de gesta se aclimataron y transformaron en el ambiente asiático, produciendo fenómenos creativos de sorprendente riqueza. Como consecuencia de este contacto cultural, se fueron creando composiciones filipinas inspiradas en modelos europeos. Con la voluntad de acercar al público filipino una de las fuentes europeas que ha contribuido a la formación del patrimonio cultural de la moderna Filipinas, en la actualidad Jeannifer Zabala e Isaac Donoso han realizado la primera traducción de la obra Tirant lo Blanch a la lengua filipina, la primera también que se hace a una lengua del Sudeste Asiático.
\end{abstract}

Palabras clave: Literatura, Corona de Aragón, Filipinas, Joanot Martorell, Tirant lo Blanch, Romancero, Filipino

Abstract: Despite the geographical distance, the literature of the Crown of Aragón has influenced the literary creation of the Philippine Archipelago. The continuous Hispanic presence since the sixteenth century introduced in the islands native literary forms from Europe. Thus, the Hispanic Romancero and books of chivalry were acclimatized within the Asian environment, producing astonishing literary phenomena. Due to this cultural contact, Philippine pieces from European models emerged. Aiming to offer to the Filipino audience the European sources that have contributed to the formation of the cultural heritage in the country, Jeannifer Zabala and Isaac Donoso have made the first translation of Tirant lo Blanch into Filipino, the first as well in a Southeast Asian language. 
Keywords: Literature, Crown of Aragón, Philippines, Joanot Martorell, Tirant lo Blanch, Romancero, Filipino

Acaba de ver la luz en Manila la primera traducción de la obra Tirant lo Blanch en lengua filipina, primera realizada a una lengua del Sudeste Asiático, traducida por Jeannifer Zabala Priel e Isaac Donoso Jiménez, y realizada en el seno del Proyecto IVITRA (http://www. ivitra.ua.es), y, en la matriz de éste, en el seno de los proyectos DIGICOTRACAM (PromETEO-2009-042, Programa de la Generalitat Valenciana «para grupos de investigación en I+D de excelencia», proyecto cofinanciado por el FEDER de la UE), el Grupo de Investigación «Traducción de clásicos valencianos» de la Universidad de Alicante (Vigrob-125UA), del Grupo de Investigación en Tecnología Educativa «Historia de la Cultura, Lingüística diacrónica y Traducción» (GITE-09009-UA), y los proyectos del Ministerio de Ciencia y Tecnología del Gobierno de España: «Gramática del Catalán Antiguo» (FFI2009-13065-Filo) y «Multilingual Digital Library of the Mediterranean Neighbourhood» (FFI2010-09064-E), y de la Seu Universitària de la Nucia (UA). El volumen, publicado en CentralBooks, está patrocinado, además, siempre en el seno de IVITRA, por la Acadèmia Valenciana de la Llengua, el Institut Ramon Llull, la Komisyon sa Wikang Filipino (Academia de la Lengua Filipina), la Pambansang Samahan ng mga Pilipinong Tagapagsalin / The National Society of Filipino Translators, la Universidad Normal de Filipinas, y la Embajada de España en Filipinas.

El filipino, una de las superlenguas del mundo hablado por más de cien millones de personas, es en la actualidad una lengua en expansión debido a la diáspora filipina desde Vancouver a Dubai. No sólo la importancia demográfica del filipino dentro de las lenguas del Sudeste Asiático, sino también la afinidad histórica y cultural de Filipinas con un patrimonio literario proveniente de la Península Ibérica, hacían de esta traducción una urgencia imperiosa.

En efecto, por sorprendente que parezca, a pesar de la distancia geográfica, la literatura de la Corona de Aragón ha ejercido una decisiva influencia en la creación literaria del Archipiélago Filipino. La presencia hispánica continuada desde el siglo XVI ha llevado formas literarias autóctonas de Europa a aclimatarse y transformarse en el ambiente asiático, produciendo fenómenos creativos de sorprendente riqueza. Así pues, el romancero hispánico de tradición oral se fue acomodando al marco asiático del Archipiélago Filipino a partir del siglo XVI. Como consecuencia de este contacto cultural, se fueron creando composiciones filipinas inspiradas en modelos europeos. En primer lugar estas composiciones se irían transmitiendo de forma oral hasta comienzos del siglo XIX, cuando eclosionaría el romancero filipino por escrito.

Inspirado por el romancero hispánico y los libros de caballerías, el auditorio filipino iría traduciendo lingüística y contextualmente los modelos europeos en producciones originales. Si bien se trataba de una literatura de cariz popular, Francisco Balagtás (1788-1862) logró formalizar el género y dar entidad a los romances métricos filipinos (awit y corrido) desde la transmisión 
oral a la literatura culta, siendo la obra maestra Florante at Laura. Romance métrico escrito en tagalo, narra la lucha de Florante por obtener el amor de la hija del Rey de Albania, Laura, en contra del conde Adolfo y la invasión de Albania por el general turco Miramolín. Como puede desprenderse, se emplean elementos totalmente exóticos al marco filipino, desde los nombres (Florante, Laura, Miramolín, etc.) hasta los escenarios (Albania, Turquía, etc.) Sin embargo, la obra no es exótica en un marco literario europeo. En efecto, en la tradición de los libros de caballerías hispánicos encontramos obras con nombres muy similares, como: Historia del invencible caballero Don OLIVANTE DE LAURA, Príncipe de Macedonia, que por sus admirables hazañas vino a ser Emperador de Constantinopla, publicada en Barcelona en 1564 y escrita por Antonio de Torquemada. Macedonia, al igual que la región vecina de Albania, estuvieron bajo el Imperio Bizantino de Constantinopla hasta el surgimiento del Imperio Otomano. Así pues, Francisco Balagtás emplea el mismo argumento reproducido en Olivante de Laura y en Tirant lo Blanch, el de la amenaza turca en el Mediterráneo oriental. Del mismo modo que Roger de Flor luchara históricamente en Grecia en ayuda del emperador bizantino de Constantinopla y Tirant lo Blanch lo hiciera de forma ficticia en la misma Constantinopla, Florante luchará en las tierras de Albania una vez caída Constantinopla contra el Miramolín turco, es decir, el Am ral-Mu'min n / نينمؤملاريم o califa del Islam, desde la forma española «Miramamolín».

Los libros de caballerías en torno a Constantinopla no serán la única influencia en el Florante at Laura filipino, sino que efectivamente el estilo de Tirant lo Blanch se repite en la obra de Balagtás. La fantasía y el exotismo de los libros de caballerías había sido denunciado en el Tirant lo Blanch a través del realismo, manifestando el desengaño de la Europa de la época ante la caída de Constantinopla y el mercantilismo reinante. Del mismo modo, Florante at Laura manifestará el realismo de un caballero que sufre y siente, como alegoría de los problemas sociales reales, en contra del escapismo y la fantasía dominante en la literatura filipina de la época ante los problemas de una nación en ciernes. En España, el realismo literario iniciado en Tirant lo Blanch culminará en Don Quixote de Miguel de Cervantes (1547-1616); en Filipinas, el realismo de Florante at Laura culminará en las obras de denuncia social de José Rizal (1861-1896), Noli me tangere y El Filibusterismo. Del mismo modo que el personaje de Tirante para la literatura española, el personaje de Florante revelará los misterios de la realidad en la literatura filipina. Como filipino del siglo XIX, Francisco Balagtás sin duda sería consciente de la historia literaria española, de la revolución que Don Quixote supuso para el mundo español y de la influencia decisiva del Tirant lo Blanch para que apareciese una obra capital como la de Cervantes. Francisco Balagtás estaba creando las bases de un compromiso social basado en la realidad, compromiso que eventualmente con el correr del siglo devendría nacionalismo.

Pero al margen de esta acción individual de Balagtás, muchos de los romances filipinos fueron compuestos de forma anónima, traduciéndose de lengua en lengua, hasta conformar un verdadero patrimonio filipino. Desde fuentes y materiales diversos, principalmente el romancero hispánico, lugares y personajes exóticos emergían en el escenario asiático de Fílipinas. De este modo es 
como podemos encontrar un buen número de romances filipinos que tienen como escenario argumental la Corona de Aragón y, específicamente, el Reino de Valencia: Salita at Buhay na pinagdaanan ni Príncipe D. Juan Tiñoso sa REINONG VALENCIA / Corrido at buhay ng principeng si D. Juan sa REYNO NANG VALENCIA / Ang calugód-lugód na búhay nang mag asauang so D. Diego Florencia at ni D. ${ }^{a}$ Juana sa CIUDAD NG VALENCIA / An macaheherac na buhay can duang magtugang na si Felizardo y Catalina na pinag orihan can saidang ama sa REINONG VALENCIA / Malodoc na agui-agui ni Trabiata-Trobador asin ni Norma sa Cahadean nin VALENCIA / Pacasaritaan ti panagbiag dagiti lima nga agcacabsat iyi REYNO A VALENCIA / Buhay na pinagdaanan ni Rodolfo na anac ni Felizardo at si Prisca sa CAHARIANG VALENCIA. La tradición valenciana de los libros de caballerías influiría en el número considerable de romances filipinos donde Valencia aparece como escenario argumental.

Finalmente, las historias provenientes de Europa que originan el romancero filipino también fueron la base de las formas dramáticas que se iban desarrollando en Filipinas. La expansión de los reinos cristianos ibéricos por el territorio de al-Andalus / سلدندأل conformó la moderna España, siendo igualmente la base de representaciones teatrales basadas en los dos bandos: el bando musulmán y el bando cristiano. De forma popular se fueron escenificando las batalles históricas o legendarias, con lo que se creó un teatro de Moros y Cristianos, normalmente vinculado a las celebraciones cristianas de las nuevas poblaciones conquistadas a los musulmanes. Con las conquistas cristianas de nuevos territorios, las representaciones de Moros y Cristianos se exportaron a América y llegaron incluso a Asia. Efectivamente, en 1637 se representa en Cavita la Gran comedia de la toma del pueblo de Corralat y conquista del Cerro, primera y prácticamente única comedia filipina que trata un tema local. Del mismo modo que los romances métricos filipinos, la Komedya o Moro-Moro desarrollará argumentos y escenarios exóticos.

El Reino de Valencia es la región española más islamizada y donde población musulmana más tiempo ha permanecido, desde el 711 al 1609. Por este motivo es la región donde nacieron las representaciones de Moros y Cristianos, siendo la ciudad de Alcoy donde al presente se celebra la más importante escenificación. Así pues, no sólo la tradición caballeresca valenciana influenció al romancero filipino, sino que el Islam de Valencia también ha sido decisivo para la gestación de formas dramáticas patrimoniales a Filipinas como la Komedya, género singular dentro del teatro asiático.

En conclusión, el mundo del Tirant lo Blanch — desarrollado en el extremo occidental asiático que representa Constantinopla- alcanzó el extremo oriental de Asia transmitiendo su universo a la formación y posterior desarrollo de la literatura filipina. La presente traducción al filipino (la primera que se hace a una lengua del Sudeste Asiático), pretende acercar al público del archipiélago una de las fuentes europeas que ha contribuido a la formación del patrimonio cultural de la moderna Filipinas. 